\title{
Research on the attribute of product design material elements based on system theory
}

\author{
Shuying Guo ${ }^{1 *}$, Jingyu Sun $^{2}$ \\ ${ }^{1}$ College of Mechanical Engineering, Jilin Engineering Normal University, Changchun, 130052, China \\ ${ }^{2}$ Jilin City Technical College, Changchun, 130052, China
}

\begin{abstract}
The main purpose of this study is to apply the theory of system to the field of product design and to research the properties of product materials. According to the sorting and analysis of the relevant research results and literature and based on the systematic method the perception attribute is studied through the humanistic characteristics of product materials; the cultural attribute is studied through the historical characteristics of product materials; the commercial attribute is studied through the economic value characteristics of product materials; the environmental attribute is studied from the perspective of the ecological and sustainable development of product materials. On this basis, the feasibility suggestions for future research in this field are put forward.
\end{abstract}

\section{Introduction}

System theory is a kind of theory based on the relationship of elements to analyze things as a whole. It focuses on the ways of interrelation, interaction and mutual influence among the components of the system and how the system can form a larger system and work in a larger system environment. The theories and methods formed by the application of system theory to different disciplines and fields have different emphases, but their purpose is to seek the methods of analyzing and solving problems for system optimization.

From the point of view of design, the material elements of a product, together with the elements of function, form, structure and color, constitute the element system of a product, while the material is the material basis for the existence of a product entity, and interacts with other element systems to jointly realize the reality of a product. Therefore, it is an important breakthrough of modern product design concept and method to apply the related concepts, ideas and methods of system and system theory to product design, to take the product as a system implementation design, and to put it into a larger system for analysis and research. From the point of view of system, the product itself is a system, which consists of function, structure, form, color, material and other elements. Each element system exists as a subsystem of the product system.

Structural modeling and processing technology is an important part of product material elements, and also the basis of product material selection. Structural modeling ability refers to the ability of materials to achieve product structure and shape, and technological performance refers to the ability of materials to adapt to the actual production process requirements. As the molding materials of industrial products, they must have excellent molding process performance, processing process performance and surface process performance, so as to improve the service life of products, the surface beautification and decoration effect of materials, and the added value of products. Therefore, this study is of great significance for the selection, design and optimization of product materials and the realization of the overall performance of the product system.

\section{Journals reviewed}

\subsection{System theory and product design}

As of the writing of this paper, 16489 journal documents have been retrieved in HowNet with the theme of "system theory". There are 11502 English articles, and the research trend is still increasing year by year. The main research topics are enterprise management and control engineering. With the theme of "system theory" and "product design", 21 periodical literatures were retrieved. Among them, there are 9 English literatures, which focus on the design process and thinking form. See Table 1 for specific data analysis.

\footnotetext{
*Corresponding author's e-mail: 29012610@qq.com
} 
Table 1. System theory and product design literature search results

\begin{tabular}{cccc}
\hline & $\begin{array}{c}\text { Literature } \\
\text { (article) }\end{array}$ & Type (article) & Proportion (\%) \\
\cline { 2 - 4 } System & 16489 & English: 11502 & 60.76 \\
theory & & Chinese: 4987 & 30.24 \\
& & & \\
System & 21 & English: 9 & 42.86 \\
$\begin{array}{c}\text { theory }+ \\
\text { product } \\
\text { design }\end{array}$ & & Chinese: 12 & 57.14 \\
\hline
\end{tabular}

From the above literature search and analysis, we can see that: from a global perspective, the academic community attaches great importance to the research of system theory and has achieved a lot of research results, but the attention and research of Chinese scholars on system theory is significantly less than that of foreign scholars. The research of applying system theory to product design only accounts for $0.1 \%$ of the total research results in the field of system theory, as an important theory and method, system theory and product The research of design combination has the advantages of deepening and expanding.

\subsection{System theory and product materials}

As of the writing of this paper, 7752 journal articles have been retrieved on HowNet with the theme of "system" and "product". There are 1052 English documents in which the research topics are mainly product enterprise management, product design, computer-aided design, etc. With the theme of "system" and "product materials", 174 periodical literatures were retrieved, 90 of which were in English. From the distribution of research topics, we can see that there are many literatures on building materials, and few literatures on product design materials. See Table 2 for specific data analysis.

Table 2. System and product material literature search results

\begin{tabular}{cccc}
\hline & Literature (article) & Type (article) & Proportion (\%) \\
\cline { 2 - 4 } System & 7752 & English: 1052 & 13.57 \\
& & Chinese: 6700 & 86.43 \\
System + & 174 & English: 90 & 51.72 \\
product & & Chinese: 12 & 48.28 \\
material & & & \\
\hline
\end{tabular}

From the above literature search and analysis, it can be seen that in the field of product design, there are few literature achievements on the research of product material elements as a system or using the method of system theory to research product materials, especially on the systematic research of product material attributes. Therefore, this project will expand and enrich the research achievements in this field.

\section{Main contents of the study}

\subsection{Perception properties of product materials}

The purpose of humanism is the most essential embodiment of design value. Humanism plays an irreplaceable role in the field of product design. On the basis of the development of material science and technology, compared with the product design which can meet people's physiological needs for materials, modern people's psychological needs for products have become complex and changeable, and have a trend of rising and developing towards the level of spiritual needs.

People's psychological demand for products is a relatively complex demand system, in which the feeling brought by materials is only a constituent element of the system, but it is as important as other elements of the demand system. People's psychological perception of product surface attributes is called material perception attributes, including tactile, visual, auditory and olfactory senses of materials.

People's psychological demand for products is a relatively complex demand system, in which the feeling brought by materials is only a constituent element of the system, but it is as important as other elements of the demand system. People's psychological perception of product surface attributes is called material perception attributes, including tactile, visual, auditory and olfactory senses of materials. For example, the sense of science and technology presented by the metal drawing process and surface texture, the sense of cleanness and luster displayed by the white ceramic materials and processes, the crystal clear feeling felt by transparent glass through different shapes, the soft, comfortable and happy feeling of the leather fabric of the sofa, the simple and delicate feeling of the matte surface texture of plastic materials, and the gas of natural wood People feel natural and fresh feeling, which belong to the perception property of materials. 


\subsection{Cultural properties of materials}

The cultural attributes of materials and crafts are only for some materials with a long history. Not all materials have cultural attributes. For example, stone materials, the ancient bluestone slab road and cobblestone road in some historical sites have their own naturally formed texture and shape, which are permeated with the long cultural charm. If properly designed or used, wood, ceramics, bamboo, paper, bronze and other materials can convey the cultural attributes of materials and technology through the product as a carrier. It can be seen that, although many product designers will neglect in the process of product design and optimization, the culture of material and technology plays an important role in meeting people's psychological needs for products.

In the process of product material selection and design, it is very important for the design and optimization of the whole product scheme to fully consider the product information that can be conveyed by the cultural attribute of the material.

\subsection{Commercial properties of product materials}

From the perspective of social economy, one of the main systematic characteristics of modern products is that products have the attributes of commodities. As one of the important elements of the product system, materials also have the attributes of Commerce. Products entering the field of marketing and service system, price positioning, promotion means, sales channels, these four elements establish a connection. Product is the carrier of marketing activities, and marketing is the goal and means for products to become commodities. Therefore, from the root, product system design has become the most fundamental reason for the success of product commercialization, and design has become a means to realize product value.

Through a large number of market research and data analysis, we can see that the only most important reason for the success of new products in the market is to reflect the uniqueness and superiority of products on the premise of meeting the needs of consumers. The creative use of new materials (smart materials, eco-environmental materials, nano materials, etc.) and new processes is just one of the important methods and means to achieve the uniqueness and superiority of products. The commercial properties of materials can be reflected not only by products, but also by their own price advantages. The price advantage includes the most reasonable purchase cost, processing cost, packaging, storage cost and transportation cost.

\subsection{Commercial properties of product materials}

How to reflect the value of design from the perspective of ecology and sustainable development has always been the concern of design researchers. Only put the design under the background of scientific development of harmonious coexistence and eternal development of human and nature, regard the whole life cycle process and natural environment of products as a life community, strive to minimize the loss and damage to nature, on this basis, meet the needs of more consumers at more levels and achieve the goal of profit for enterprises, so as to achieve a virtuous cycle and sustainable development From the perspective of development, the value of design can be truly realized.

The environmental properties of materials are the properties that affect the environment and people in the whole life cycle of product design, production, transportation, sales, use and waste. Therefore, in the process of product design, especially in the process of material optimization, the environmental properties of materials and processes should be analyzed and studied to achieve the design objectives and realize the design value.

\section{Main contents of the study}

From the point of view of modern product system optimization process, comprehensive consideration and study of physical and chemical properties, perception properties, cultural properties, commercial properties and environmental properties of materials can make design materials and processes achieve innovation in design objectives, methods and universality. Its contribution lies in providing better service for product design and realizing the value of product design.

Based on the theory and method of system theory, this paper makes an in-depth study on the attributes of material elements in product design. The results can be used for reference to the research in this field, and enrich and develop the systematic method system of product design.

\section{References}

1. Guo, S.Y. (2019) Research on product system optimization. Jilin People's Press, Changchun.

2. Kapkin E., Joines S., (2018)Aninvestigation into the relationship between product for mand perceived meanings, Int. J. Ind. Ergon. 67:259-273

3. Karana E., Pedgley O., Rognoli V., (2015) On materials experience, Des. Issues 31: 16-27

4. Lore V.,Els D. B., Ingrid M., Elvin K. (2020) Materials \& Design., 1-15

5. Piselli A., Baxter W., Simonato M., Del Curto B., Aurisicchio, M. (2018) Development and evaluation of a methodology to integrate technical and sensorial properties in ma- terials selection, Mater. Des. 153: 259-272

6. S. Wilkes, S. Wongsriruksa, P. Howes, R. Gamester, H. Witchel, M. Conreen, Z. Laughlin, M. Miodownik, (2016)Design tools for interdisciplinary translation of material experiences, Mater. Des. 90 $1228-1237$ 